\title{
QUANDO A VOZ DO ELEITOR POUCO ECOA PARA OS CANDIDATOS: ESTUDO DE CASO DO HGPE EM CURITIBA 20121
}

\author{
Ricardo Tesseroli ${ }^{2}$ \\ Luciana Panke ${ }^{3}$
}

\section{Resumo}

O reconhecimento do início da campanha eleitoral propriamente dita é marcado pela veiculação do Horário Gratuito de Propaganda Eleitoral (HGPE) no Rádio e Televisão. O HGPE é um importante espaço de persuasão e exposição do discurso das elites políticas. Com base nos dados obtidos pelo Grupo de Pesquisa "Comunicação Eleitoral", do Programa de Pós-Graduação em Comunicação, da Universidade Federal do Paraná (UFPR), este trabalho pretende refletir sobre o primeiro turno das campanhas eleitorais dos três principais candidatos à prefeitura de Curitiba em 2012, Gustavo Fruet, Ratinho Júnior Luciano Ducci. Realizando uma análise de conteúdo (AC) comparativa das temáticas de campanha abordadas nos programas dos três candidatos durante o HGPE televisivo e radiofônico. Estes temas são comparados com a opinião dos eleitores, indicada nas pesquisas eleitorais realizadas por institutos, sobre os principais problemas que Curitiba enfrentava naquele momento. Nossa hipótese é de que, os principais problemas apontados pela população estariam contemplados durante a propaganda eleitoral. O estudo constatou a confirmação parcial de tal hipótese.

Palavras-Chave: Comunicação Eleitoral, Curitiba, HGPE, Eleições 2012.

\section{Resumen}

En Brasil, el inicio de una campaña electoral es comprobado por la transmisión de los programas electorales en radio y televisión (HGPE). Eses contenidos son fundamentales para transmitir los discursos de las elites políticas. Con las informaciones del Grupo de Investigación Comunicación Electoral (UFPR) ese artículo estudia las campañas de Gustavo Fruet, Ratinho Júnior Luciano Ducci en la primera vuelta de las elecciones a alcaldía de Curitiba. Con un análisis de contenido comparativo entre los temas de campaña y los datos de los institutos de opinión pública a respecto de los anhelos de la población. Creemos que los problemas que la gente indicaba estarían en las propuestas de las campañas electorales. El estudio observó una confirmación parcial de esa idea.

Palabras-Clave: Comunicación Electoral, Curitiba, HGPE, Elecciones 2012.

\begin{abstract}
The accreditation of the start of the political campaign itself is defined by the placement of the Free Political Advertising Time (HGPE) in Radio and Television stations. The HGPE is an important space of persuasion and exposure of the political elites' speeches. Based on the data obtained by the "Comunicação Eleitoral" Research Group, created by students of the Communication Graduate Program of the Federal University of Paraná (UFPR), this paper aims to reflect on the first round of the political campaigns placed by the three leading candidates for mayor of Curitiba, in 2012, Gustavo Fruet, Ratinho Júnior e Luciano Ducci. Performing a comparative content analysis (CA) of campaign themes addressed in the programs broadcast by each of the three candidates during the HGPE aired in television and radio stations. These themes are compared with the opinion of voters indicated in the polls carried out by institutes, addressing the main problems Curitiba was facing at that moment.

\footnotetext{
${ }^{1}$ DOI deste artigo: $10.5380 /$ recp.v6i2.38933.

2 Mestre em Comunicação pela Universidade Federal do Paraná, integrante do grupo de pesquisa em “Comunicação Eleitoral”. E-mail: rgtesseroli@gmail.com.

3 Pós-doutorado em Comunicação Política na Universidade Autônoma Metropolitana (UAM- México). Doutora em Ciências da Comunicação (USP); Professora da Universidade Federal do Paraná na graduação em Comunicação Social (Publicidade e Propaganda) e do Programa de Pós-Graduação em Comunicação. Líder do grupo de Pesquisa "Comunicação Eleitoral". Autora dos livros "Lula - do sindicalismo à reeleição" (SP, Horizonte, 2010) e "Campañas electorales para mujeres - retos y tendencias" (México,Piso15, 2015) e-mail lupanke@gmail.com
} 
We believe that the main issues stated by the population were covered during the political campaign. The study found partial confirmation of this theory.

Keywords: Electoral Communication, Curitiba, HGPE, 2012 Election.

\section{INTRODUÇÃO}

A campanha de 2012 para prefeito em Curitiba apresentou um cenário atípico e competitivo. Acostumada com eleições polarizadas, pela primeira vez na história, Curitiba possuía três candidatos com chances reais de vitória: Gustavo Fruet (PDT), Luciano Ducci (PSB) e Ratinho Junior (PSC) ${ }^{4}$. Ducci tentou a reeleição após ter assumido o cargo em março de 2010, quando o então prefeito, Beto Richa (PSDB), deixou o cargo para ficar apto a concorrer ao governo estadual. Ele formou a maior coligação da disputa, com 15 partidos aliados, somando mais de 10 minutos de HGPE a cada bloco de meia hora.

Gustavo Fruet foi o candidato com o segundo maior tempo. Em uma coligação formada por PDT, PT e PV, teve seis minutos de HGPE. O deputado federal, oriundo de uma tradicional família de políticos do Paraná, iniciou a campanha após ter sido o candidato a senador mais votado na capital paranaense dois anos antes.

Por sua vez, Ratinho Junior liderou uma coligação de quatro partidos - PSC, PR, PCdoB e PTdoB, o que lhe rendeu praticamente quatro minutos por bloco de HGPE. A candidatura de Ratinho Junior havia ganhado força em 2010, quando ele foi reeleito deputado federal com o maior número de votos no Estado 5 .

A apuração no dia 7 de outubro de 2012 definiu que Ratinho Junior e Gustavo Fruet disputariam o segundo turno ${ }^{6}$. O candidato do PSC foi o mais votado, com 31,17\% do total, e o pedetista ficou em segundo lugar, com 24,89\% dos votos. A diferença para Ducci, o terceiro colocado, foi de pouco mais de quatro mil votos, deixando o candidato do PSB com $24,48 \%$ do total. O resultado contrariou a tendência apontada pelos institutos de pesquisa Ibope e Datafolha, que realizaram levantamentos durante todo o período eleitoral. Desde o início da campanha no rádio e na TV, a previsão era de que Luciano Ducci estivesse

\footnotetext{
${ }^{4}$ Ao todo a capital paranaense teve oito candidatos ao cargo de prefeito. Luciano Ducci (PSB), concorreram Gustavo Fruet (PDT), Ratinho Júnior (PSC), Rafael Greca (PMDB), Bruno Meirinho (PSOL), Alzimara Bacellar (PPL), Avanílson Araújo (PSTU) e Carlos Moraes (PRTB) ${ }^{4}$. Este último, porém, teve o registro de candidatura indeferido pouco menos de um mês antes do primeiro turno, deixando a disputa.

5 TSE. Resultado das eleições de 2010. TSE, Brasília, 2010. Disponível em: http://www.tse.jus.br/eleicoes/eleicoes-anteriores/eleicoes-2010/estatisticas. Acesso em 17 de junho de 2013.

${ }^{6}$ http://www.tse.jus.br/eleicoes/estatisticas/estatisticas-eleicoes-2012
} 
no segundo turno contra Ratinho Jr, já que Fruet chegou a figurar 14\% abaixo do segundo colocado nas intenções de voto restando pouco menos de um mês para a eleição ${ }^{7}$.

É neste contexto que este estudo se ambienta. Com base nos dados do Grupo de Pesquisa Comunicação Eleitoral, do Programa de Pós-Graduação em Comunicação, da Universidade Federal do Paraná, realizamos uma análise dos programas do HGPE veiculados no rádio e TV, dos candidatos de Gustavo Fruet (PDT), Luciano Ducci (PSB) e Ratinho Junior (PSC) e as pesquisas divulgadas pelo Ibope desde o período pré-eleitoral, até o último dia de exibição do HGPE, compreendendo entre 29 de março e 04 de outubro de 2012. Nosso objetivo é averiguar se os temas apontados pelos moradores coincidiam com os presentes nas campanhas.

\section{O HORÁRIO GRATUITO DE PROPAGANDA ELEITORAL}

De acordo com Peths e Leal (2013, p. 90-91), "o modelo do HGPE que conhecemos hoje surgiu por conta da necessidade de disciplinar as propagandas partidárias e dar oportunidades iguais de exposição dos partidos políticos". Algumas tentativas foram feitas ao longo da recente história brasileira, como no fim do Estado Novo, em 1946, e também com o código eleitoral de 1950. Entretanto, de uma maneira geral, a legislação tratava das questões inerentes ao rádio, meio de comunicação mais utilizado naquela época. A solução criada após o Estado Novo não era, de fato, uma distribuição democrática das campanhas eleitorais, já que a emissora não era obrigada a veicular os programas de partidos que não fossem de seu interesse. Desta forma, os veículos poderiam negar a veiculação de ideais da oposição. (PERHS; LEAL. 2013, p.91)

Isso só mudou em 1962, com a entrada em vigor da Lei 4.115. A legislação, além de solucionar esse problema, regulamentou o tempo do HGPE de cada partido, de acordo com o tamanho de suas bancadas nos legislativos federal, estadual e municipal. Contudo, somente em 1965, no período da Ditadura Militar, foi instituído no país um código eleitoral para regulamentar a veiculação dos programas em televisão. A lei $\mathrm{N}^{\circ} 4.115$, de 15 de julho

\footnotetext{
${ }^{7}$ G1. Em Curitiba, Ducci tem 31\%, Ratinho Jr, 30\% e Fruet, 16\%, diz Ibope. G1 Paraná, Curitiba, 14 set 2012. Disponível em: http://g1.globo.com/pr/parana/eleicoes/2012/noticia/2012/09/em-curitiba-ducci-tem-31ratinho-jr-30-e-fruet-16-diz-ibope.html. Acesso em 17 de junho de 2013.
} 
de 1965, tornou-se responsável por um importante avanço na legislação eleitoral, mesmo em uma época em que a TV ainda não era o principal meio de comunicação do país.

A veiculação da propaganda eleitoral alerta a população de que é hora de pensar nas eleições. Segundo enfatizam Panke e Cervi (2011), o HGPE dá visibilidade a esse momento e desperta o eleitor para o pleito.

Além da função informativa e de servir como fonte distintiva das imagens públicas dos candidatos, o HGPE tem outro importante papel nas disputas eleitorais brasileiras. Ele indica aos eleitores o início do "tempo da política", o momento em que a política entra nos espaços privados das famílias através da televisão e do rádio, invertendo a lógica do debate político. Até o início do horário eleitoral o cidadão comum só acessa informações sobre candidatos em espaços públicos e as leva para a esfera privada - caso tenha interesse no assunto. Já com o HGPE essa lógica se inverte. As informações políticas surgem no espaço privado e são "levadas" para o debate em espaços públicos. É graças a essa "inversão" da privacidade dos eleitores que as campanhas políticas ganham importância para o debate público e os critérios de escolha dos candidatos podem ser comparáveis (PANKE; CERVI, 2011, p. 392).

Os autores sustentam que, até o início da propaganda eleitoral gratuita, as discussões sobre as eleições acontecem, em sua maioria, na esfera pública e nem sempre são levadas para dentro das suas casas. A veiculação do HGPE faz com que essa ordem se inverta e a discussão política entre no âmbito privado das famílias e possa fazer parte do seu cotidiano.

Magalhães (1995) reforça a ideia de que a propaganda eleitoral tira os eleitores da inércia. "O HGPE deve retirar os indivíduos de um contexto no qual suas preocupações estão estruturadas em função dos problemas do cotidiano e transformá-los em um público eleitoral, com o mínimo de atenção ao processo que lhes demanda atenção" (MAGALHÃES, 1995, p. 129). Ele tem também, entre outras atribuições, o potencial de democratizar a campanha eleitoral já que possibilita a todos os candidatos e partidos estarem no rádio e na TV, utilizando o espaço que lhes é destinado. "Através dele, os partidos e candidatos têm assegurado a presença no rádio e na televisão independentemente de critérios e interesses econômicos e políticos. O princípio que motivou a criação do Horário Eleitoral foi o reconhecimento por parte do direito eleitoral brasileiro de que a liberdade de voto implica necessariamente o direito do cidadão à informação isenta e ao debate, baseado no pluralismo ideológico" (VEIGA, 2001, p. 95). Entre outras atribuições, o HGPE também se mostra como um espaço de potencial democratização da representação política, já que possibilita para todos os candidatos e partidos um espaço no rádio e na TV durante o período. 
Para Albuquerque (1999), o HGPE brasileiro possui um formato consolidado e consagrado, mesmo apresentando diferenças em relação a outros países que possuem algum tipo de propaganda eleitoral gratuita. Embora regulamentado na década de 60, foi somente após a redemocratização do país que o HGPE se consolidou. Albuquerque enfatiza que o HGPE na TV tem sido realizado no país de forma "errática e descontínua" (ALBUQUERQUE, 1999, p.45), atribuindo, entre as razões, o Golpe Militar em 1964 e o posterior regime que se instituiu. Por outro lado, o autor enfatiza que esse sistema - que dotou o Brasil de uma infraestrutura de comunicação capaz de atingir todo o país -, possibilitou que, após 1985, o HGPE pudesse se firmar como instrumento político, auxiliando na retomada da democracia.

Passado o período antidemocrático, foram as constantes mudanças na legislação eleitoral que contribuíram para a descontinuidade da utilização do HGPE. Muitas delas ocorreram por meio de regulamentação, a maioria influenciando na divisão do tempo entre os partidos e também sobre questões específicas de produção de conteúdo e veiculação. As fórmulas criadas para orientar a divisão dos tempos foram alteradas em praticamente todas as eleições, desde 1985 até a primeira década dos anos 2000, sem que, entretanto, se tenha conseguido alcançar um critério definitivo.

[...] desde 1985, as mudanças por que tem passado a legislação eleitoral relativa à propaganda política na televisão têm sido erráticas, e não coerentes, motivadas antes pelo interesse casuístico de forças políticas do que por uma evolução no modo de se entender o papel da propaganda política na televisão: de um formato liberal de 1985 a 1992, passasse a um formato ultra-restritivo em 1994, a um formato ultra-liberal em 1996 e a um formato relativamente restritivo em 1998. Em tais condições, não é cabível esperar do estilo comunicativo do HGPE uma evolução consistente, mas sim um contínuo esforço de adaptação às regras da lei (ALBUQUERQUE, 1999, p. 52-53).

O que Albuquerque enfatiza é que, no Brasil, o Estado vem, desde a criação do HGPE, intervindo diretamente na sua regulamentação e com isso, influenciando a maneira de produção e veiculação. Desde a redemocratização, ocorreram mudanças na legislação eleitoral em praticamente todas as eleições. Para Jorge (2007), "o Estado intervém claramente no sentido de minimizar ou contrabalançar o poder dos meios de comunicação privados" (JORGE, 2007, p. 128). Quando essas mudanças não ocorrem na legislação pelo código eleitoral, eram efetuadas por resoluções do TSE, o que fez com que as coordenações de campanha, além da preocupação inerente às questões do marketing eleitoral, tivessem que atender todos os aspectos legais para enquadrar os programas do HGPE à legislação. 
Com isso os programas ganharam nova configuração a cada eleição. Ora não podiam ser produzidos com imagens externas, ora ficava proibido o uso de vinhetas e efeitos especiais, até mesmo a presença de pessoas que não fossem os próprios candidatos, sob duras penalidades aos que desrespeitassem as regras.

Retornando ao pensamento de Albuquerque (1999), podemos destacar que o autor enfatiza três principais problemas enfrentados ao longo da história pelo horário eleitoral. São questões que perpassam pelo horário, formato de veiculação, tempo que as campanhas têm para produção dos programas e ainda, o fato de ser exibido um programa "colado" ao outro. Isso pode fazer com que os candidatos apresentem informações diferentes sobre um mesmo tema fazendo com que o telespectador/eleitor desconfie do que esta sendo divulgado. $\mathrm{O}$ autor relata argumenta que:

Não obstante as sucessivas mudanças na regra do jogo, um mesmo conjunto de problemas tem, a cada edição, desafiado os responsáveis pela propaganda eleitoral levada ao ar no HGPE. Três problemas poder ser destacados: $\mathrm{O}$ isolamento do HGPE em relação à programação normal da televisão; a necessidade de adaptar o conteúdo das transmissões a um quadro temporal preestabelecido; os problemas de informação derivados da concentração da campanha em diversos candidatos em um mesmo bloco (ALBUQUERQUE, 2004. p.468-469).

Já, de acordo com Miguel (2004) o HGPE propicia duas vantagens. A primeira é a diminuição da influência do dinheiro nas campanhas, já que é o Estado que arca com os gastos da veiculação da propaganda eleitoral. Esse ponto é bem relativo, pois a produção desse conteúdo demanda bastante investimento, destacando-se os candidatos que podem bancar uma boa produção de rádio e TV. Os candidatos com pouca verba ficam prejudicados pois a falta qualidade de produção fica evidente e depõe contra eles. A segunda vantagem, conforme Miguel, é a redução da influência dos meios de comunicação jornalísticos, pois possibilita que os próprios candidatos e partidos construam a sua agenda de assuntos, selecionando as questões que consideram mais importantes.

O tempo de exposição de cada partido é considerado um ponto decisivo para a formação de coligações, uma vez que são altamente valorizados. Conforme enfatizam Panke e Cervi (2011), “...embora tenha nascido sob o propósito de oferecer espaços proporcionalmente igualitários às candidaturas, a diferença entre a qualidade de produção dos programas e o tempo destinado à sua veiculação, contrastam com o propósito inicial" (PANKE, CERVI, 2011, p. 391). A distribuição dos horários reservados à propaganda eleitoral é feita entre os partidos e coligações que tenham representação na Câmara dos 
Deputados, seguindo dois critérios: um terço do tempo dividido de forma igualitária e dois terços, proporcional ao número de representantes dos partidos na Câmara dos Deputados, considerando, no caso das coligações, o resultado da soma do número de representantes de todos os partidos que a integram. Esse cálculo faz com que partidos com maior número de deputados federais tenham tempo de televisão maior do que partidos com baixa representação na Câmara. Cervi (2010) aponta esse fato como um dos principais motivos que gera desigualdade na distribuição do tempo do HGPE. "Por esse motivo, não se deve esperar uma distribuição equitativa entre todos os concorrentes como uma conseqüência natural da organização. Pelo contrário, por ser moeda de troca, pode entrar no cômputo dos acordos entre cúpulas partidárias" (CERVI, 2010, p. 15).

Com a massificação da campanha eleitoral em rádio e TV, é possível para a maioria dos eleitores, o acompanhamento das propostas veiculadas no HGPE. Para Schmitt, Carneiro e Kuschnir (1999), “...o horário eleitoral é com toda certeza uma das duas ou três fontes de informação política mais importante para a população" (SCHMITT, CARNEIRO e KUSCHNIR, 1999, p. 287). Embora não obrigatoriamente os eleitores acompanhem estes programas integralmente ou diariamente, o HGPE os orienta com as informações transmitidas.

No entanto, mesmo com a semelhança de serem meios de comunicação de massa eletrônicos, o rádio e a TV apresentam linguagens e formatos distintos. Em consequência dessas diferenças, a estratégia eleitoral procura adaptar o conteúdo da sua campanha às características de produção técnica desses meios de comunicação para construir uma imagem do candidato. Para Silveira (2000), o marketing eleitoral busca um enquadramento dos candidatos na construção dessas imagens, essencialmente simbólicas, no qual as características negativas devem ser eliminadas ou neutralizadas e aspectos vistos como positivos ou estejam em sintonia com a percepção dos eleitores devem ser valorizados.

Ao enumerar fatores que influenciam a decisão na hora do voto, Almeida (2008) é enfático ao afirmar que o cidadão, entre outros aspectos, avalia o candidato que apresenta as melhores propostas para solucionar os principais problemas do eleitorado. De acordo com o autor,

[...] o eleitor leva em conta as seguintes informações ao escolher o seu governante: 1. Quem tem o poder de combater quais problemas. 2. Qual é o principal problema que atinge a minha vida atualmente. 3 . Dentre os candidatos que estão pedindo seu 
voto, qual deles está dizendo que vai resolver aquilo que considero ser o principal problema. 4. Qual candidato tem autoridade, tem o currículo, que permite antever que ele realmente vai tentar resolver este problema (ALMEIDA, 2008, p. 67).

Neste sentido, percebe-se que um dos aspectos da dinâmica de uma campanha eleitoral gira em torno da resolução dos problemas apontados pela comunidade. Esse ponto é tido como um dos principais fatores de êxito para uma campanha, tanto que Almeida (2008) afirma que o candidato não pode responsabilizar o eleitor caso seja derrotado em uma eleição depois de fazer uma campanha em que o centro de discussão não era o principal problema do eleitorado (ALMEIDA, 2008, p.7).

Em consonância com o pensamento de Almeida (2008), Oliveira, Romão e Gadelha (2012) valorizam a utilização das pesquisas eleitorais.

É importante que o estrategista descubra qual é o grande tema da campanha. Os eleitores têm desejos, ou melhor, demandas em relação à administração. Tem-se a hipótese de que essas demandas são advindas de problemas de contexto social, os quais não foram solucionados ou amenizados pela gestão atual. O grande tema da campanha significa, portanto, um problema a ser solucionado, pois o eleitor assim deseja.

Com a colaboração de pesquisas qualitativas, é possível identificar os problemas da cidade, estado ou do país. Diante da identificação, o candidato oferecerá propostas e soluções para tais problemas no percurso eleitoral. Por exemplo: pesquisa revela que o trânsito é o principal problema do recifense ou do curitibano. Em virtude disso, o candidato oferecerá proposta com a intenção de solucionar esse problema. É possível que na disputa eleitoral exista vários grandes temas. Porém, o candidato deve escolher os temas que mais preocupam o eleitor (ou exigem solução) (OLIVEIRA, ROMẪ; GADELHA, 2012, p. 203).

Portanto, compõem as estratégias eleitorais, as supostas soluções para resolver os problemas que mais afligem a população. Será do marketing eleitoral, a responsabilidade de trazer esses temas para a discussão pública, de tirá-los dos relatórios de pesquisas, determinar das estratégias de persuasão mais eficazes para atingir o eleitor e apontar as respectivas soluções. De acordo com Silveira (2000), o candidato deve mostrar que "representa a melhor alternativa para o enfrentamento dos problemas ditos principais e como seus adversários não são os mais indicados para esta tarefa" (SILVEIRA, 2000, p.130).

Para fazer isso, é primordial, de acordo com a autora, uma análise criteriosa do quadro político, das questões conjunturais relevantes, das preocupações e expectativas do eleitor em relação aos principais problemas do momento. 
O candidato obtém seu melhor desempenho quando consegue se posicionar bem estrategicamente, utilizando conhecimentos conjunturais mais relevantes para mostrar a correção das suas propostas, criando, através da sua ação fatos politicamente relevantes e orientando a sua atividade de forma sintonizada com as preocupações e expectativas predominantes - não somente em relação aos temas considerados mais importantes, mas também a postura adequada ao momento (SILVEIRA, 2000, p.129-130).

Este comportamento do candidato, visando persuadir o eleitor, vai ao encontro de alguns estudos de Downs (2002). De acordo com o autor, os eleitores almejam obter o maior número de benefícios que o governo possa proporcionar. Paiva (2010) complementa esse pensamento explicitando que "por sua vez, o governo (e os partidos) tem como o fim se manter no poder e para tanto necessita maximizar seu apoio eleitoral, oferecendo aos indivíduos aquilo que eles desejam" (PAIVA, 2010, p. 34). Nesse ponto, os candidatos, em uma disputa deveriam: "... satisfazer os interesses do eleitorado inteiro, por que não sabem de antemão quem será indiferente e uma vez eleitos, eles sabem que os cidadãos que eram indiferentes poderão votar no futuro. Assim, os partidos competem entre si para atrair os votos potenciais de homens que se abstiveram anteriormente, assim como os votos reais daqueles que votaram" (Downs, 2002, p. 281)

A exposição de que teria interesse em satisfazer os desejos do eleitorado, está ligado à possibilidade que os candidatos têm de saber quais são as demandas. Lavareda (2009) destaca que é indispensável ouvir a "agenda do cidadão" (LAVAREDA, 2009, p. 77). Segundo o autor, uma das tarefas mais complicadas de uma campanha é "imaginar os principais problemas, as questões que prometem estar presentes no quadro de referências da população durante a campanha eleitoral", (LAVAREDA, 2009, p.77).

Para o autor, é necessário que seja organizado um estudo que aponte as necessidades dos eleitores, suas percepções e os caminhos com respostas à demanda da população. Não "imaginar" de forma subjetiva, mas pesquisar de forma profissional as necessidades do eleitor, com o apoio de pesquisas de opinião pública. "Qual delas vai ocupar o topo do ranking? Será a questão do emprego? Será o combate à violência ou a discussão de como melhorar o trânsito e o transporte público? Que importância terão os problemas da saúde. E quando ouvirem falar em saúde, no que as pessoas vão pensar? Estarão mais preocupadas com as filas nos hospitais, com a distribuição gratuita de remédios, ou com a visita domiciliar das equipes de saúde? E quanto às filas, qual é a sua expectativa? Eliminá- 
las com a contratação de mais médicos e pessoal de enfermagem, ou através da construção de mais postos de saúde ou policlínicas?” (LAVAREDA, 2009, p.77).

Lavareda propõe, além do levantamento temático, a realização de estudos para viabilizar as soluções para cada caso.

O estudo deve, em um esquema parecido, oferecer respostas para cada uma das áreas mais problemáticas: educação, formação profissional, combate as drogas, inflação, agricultura, meio ambiente, entre outras. É certo que para cada esfera em disputa - federal, estadual e municipal - os problemas concernidos tem diferença. Algumas, óbvias. Dificilmente se discutirá, por exemplo, detalhes da inflação, numa eleição municipal. Outras, nem tanto. A segurança Pública hoje frequenta o temário de qualquer eleição, em qualquer nível, embora naturalmente desperte expectativas de atuação diferentes em cada um deles. Que expectativas? (LAVAREDA, 2009, p. 77-78).

Tem-se, neste ponto, uma relação estreita entre a comunicação com o público e o uso das pesquisas como base de dados. Pois, com elas, são encontradas as informações para construir o discurso eleitoral, adequando o posicionamento do candidato e guiando as propostas de acordo com aquilo que aflige o eleitor. Saber como a população pensa, age e reage é imprescindível para a definição de estratégias, sendo a pesquisa eleitoral uma das ferramentas mais indicadas para a obtenção dessas informações. De acordo com Baquero (1995), as pesquisas eleitorais são um mecanismo para orientar ações, fazer a estruturação dos discursos e formar a opinião pública, uma vez que seus dados são utilizados no planejamento de comunicação eleitoral.

Conforme as pesquisas vão sendo divulgadas, o candidato pode ir adequando sua campanha, para conservar a tendência de alta ou reverter o quadro de queda nas intenções de voto. "A pesquisa é instrumento de informação do eleitor e de orientação para o candidato" (ROMÃO 2010. p. 242). Os dados apontados por uma pesquisa também mostram, por exemplo, a melhor maneira de um candidato apresentar-se perante o eleitor, temas a serem abordados, como elaborar seu plano de governo e também, em um período pré-eleitoral, direcionar quais alianças podem ser mais ou menos vantajosas.

\section{TEMÁTICAS EM CURITIBA}

Ao longo do período que abrangeu a pré-campanha e a campanha eleitoral no primeiro turno, foram divulgadas 14 pesquisas de intenção de voto em Curitiba. Cinco institutos realizaram sondagens eleitorais na capital paranaense: Ibope, Datafolha, Vox Populi, Datacenso e IRG Consultoria. Desses, são utilizadas para este estudo as cinco 
pesquisas de intenção de voto realizadas pelo Ibope. Esta opção se baseia no fato de ser o único instituto que realizou, periodicamente, pesquisas nos períodos pré-eleitoral e eleitoral, além de ter disponibilizado o relatório de pesquisa completo para download. As pesquisas que compõem o corpus para análise quantitativa foram divulgadas entre os dias 29 de março e 03 de outubro de 2012. São elas: pesquisa Ibope de 30/03 $; 10 / 08^{9}, 24 / 08^{10}, 14 / 09^{11}$ e $01 / 10^{12}$.

No período regulamentado de propaganda eleitoral, entre 21 de agosto e 04 de outubro de 2012, foram veiculados 19 programas eleitorais de cada um dos candidatos, com duas exibições diárias, das $13 \mathrm{~h}$ às $13 \mathrm{~h} 30$ e das $20 \mathrm{~h} 30$ às $21 \mathrm{~h}$, nas segundas, quartas e sextasfeiras na televisão e das $7 \mathrm{~h}$ as $7 \mathrm{~h} 30$ e $12 \mathrm{~h}$ às $12 \mathrm{~h} 30$, nos mesmos dias, no rádio, de acordo com a resolução $n^{\circ} 23.341$ do Tribunal Superior Eleitoral ${ }^{13}$.

A metodologia emprega na pesquisa corresponde à Análise de Conteúdo (AC) para o levantamento quantitativo dos temas apresentados tanto nas pesquisas quanto no HGPE. Os programas eleitorais do HGPE dos três candidatos foram coletados, decupados e categorizados pelo Grupo de Pesquisa em Comunicação Eleitoral da Universidade Federal do Paraná, no total de 114 programas. Depois de transcritos, foram classificados em 14 temáticas: Administração Pública; Assistência social; Candidato; Cidade; Desqualificação; Educação; Esporte, lazer e cultura; Infraestrutura; Meio ambiente; Mobilidade urbana; Saúde; Segurança e Religião, de acordo com proposta metodológica já aplicada pelos integrantes ${ }^{14}$. A partir da contabilização, calculou-se a incidência dos temas apresentando a porcentagem em cada programa e no total da veiculação durante o período eleitoral no HGPE. Para este trabalho não será contabilizado os percentuais referentes a temática Candidato, por entender que este estudo não abordará questões relacionadas a personalização das campanhas.

\footnotetext{
8 Pesquisa registrada no TRE-PR sob o protocolo PR-00001/2012. Disponível em www.ibope.com.br ${ }^{9}$ Pesquisa registrada no TRE-PR sob o protocolo PR-00040/2012. Disponível em www.ibope.com.br ${ }_{10}$ Pesquisa registrada no TRE-PR sob o protocolo PR-00066/2012. Disponível em www.ibope.com.br ${ }^{11}$ Pesquisa registrada no TRE-PR sob o protocolo PR-00162/2012. Disponível em www.ibope.com.br 12 Pesquisa registrada no TRE-PR sob o protocolo PR-00462/2012. Disponível em www.ibope.com.br 13 Disponível em: http://www.tse.jus.br/arquivos/r23341-normas-e-documentacoes-eleicoes-2012. Consultado em 12/07/2014.

${ }^{14}$ Para saber mais sobre a metodologia recomenda-se a leitura de outros resultados do Grupo. As temáticas propostas provêm de estudos realizados pelo grupo de estudos "Comunicação Eleitoral", UFPR, sob a orientação da Prof. Luciana Panke (PANKE, 2011), presente também nas considerações de Cervi e Panke (2011). A metodologia foi apresentada durante o V Congresso da Associação Brasileira dos Pesquisadores em Comunicação e Política - Compolítica. Anais disponíveis em http://www.compolitica.org/home/wpcontent/uploads/2013/05/GT-09-Propaganda-e-Marketing-Pol\%C3\%ADtico-Luciana-Panke.pdf
} 
Nas pesquisas divulgadas, o Ibope incluiu em seus questionários uma pergunta que buscou identificar os principais problemas enfrentados pela população de Curitiba. As alternativas de respostas foram divididas nas seguintes temáticas: Calçamento de ruas e avenidas; Saúde; Educação; Trânsito; Transporte coletivo; Assistência social; Geração de emprego; Iluminação pública; Limpeza pública; Abastecimento de água; Segurança pública; Habitação; Meio ambiente; Impostos e taxas; Administração pública; Atividades esportivas, opções de lazer e Corrupção.

Constatamos equivalência das temáticas categorizadas pelo Grupo de Estudos e das apresentadas ao eleitor através dos questionários do Ibope. Para que fosse possível efetuar uma comparação precisa entre as duas categorizações, a temática "Trânsito" dos questionários do Ibope foi equiparada à temática "Mobilidade Urbana” dos estudos do grupo de pesquisa; e a temática "Calçamento de ruas e avenidas" com "Infraestrutura Urbana". Optamos por tal adequação devido à similaridade das áreas e também para que fosse possível a comparação entre as respostas do Ibope e as temáticas do grupo de estudos.

Buscamos, com a análise quantitativa das pesquisas e dos programas do HGPE, responder se os assuntos apontados nas pesquisas eleitorais como principais problemas enfrentados pela população de Curitiba foram ou não os que estiveram mais presentes durante o HGPE, coincidindo com o que, no marketing eleitoral, chamam-se de "grandes temas de campanha” (OLIVEIRA, ROMÃO, GADELHA, 2012, p. 203) Para isso será verificada essa equivalência de temática a partir da comparação dos dados do Ibope com os verificados pelo grupo de pesquisa.

Os assuntos predominantes de campanha, ou os grandes temas, são abordados agora em uma perspectiva comparada, a partir da análise quantitativa das pesquisas eleitorais. Nos relatórios do Ibope divulgados nos dias 29/03, 10/08, 24/08, 14/09 e 01/10/2012, disponibilizadas para download no site do instituto ${ }^{15}$ e, portanto, disponíveis aos estrategistas, consta a seguinte pergunta: "Desta lista de áreas onde as pessoas vêm enfrentando problemas de maior ou menor gravidade, por favor, diga qual é a área em que, na sua opinião, a população de Curitiba está enfrentando os maiores problemas?”. As cinco respostas principais, de acordo com cada uma das pesquisas, foram as seguintes:

${ }^{15}$ www.ibope.com.br 
Aqui está uma lista de áreas onde as pessoas vêm enfrentando problemas de maior ou menor gravidade. Diga qual é a área onde, na sua opinião, a população de Curitiba esta enfrentando maiores problemas.

Tabela 1 - Problemas Urbanos

\begin{tabular}{c|c|c|c|c|c|c|c}
\hline \hline Tema & $\mathbf{3 0 / 0 3}$ & $\mathbf{1 0 / 0 8}$ & $\mathbf{2 4 / 0 8}$ & $\mathbf{1 4 / 0 9}$ & $\mathbf{0 1 / 1 0}$ & Média & Posição \\
\hline Saúde & $43 \%$ & $35 \%$ & $46 \%$ & $38 \%$ & $42 \%$ & $40,8 \%$ & $1^{\circ}$ \\
\hline Segurança & $21 \%$ & $31 \%$ & $20 \%$ & $23 \%$ & $22 \%$ & $23,4 \%$ & $2^{\circ}$ \\
\hline Educação & $9 \%$ & $6 \%$ & $10 \%$ & $10 \%$ & $6 \%$ & $8,2 \%$ & $3^{\circ}$ \\
\hline Trânsito & $5 \%$ & $8 \%$ & $7 \%$ & $5 \%$ & $7 \%$ & $6,4 \%$ & $4^{\circ}$ \\
\hline Infraestrutura & $6 \%$ & $4 \%$ & $4 \%$ & $5 \%$ & $7 \%$ & $5,2 \%$ & $5^{\circ}$ \\
\hline
\end{tabular}

Fonte: Ibope 2012 - tabulação -os autores.

As respostas, em todas as cinco averiguações, assinalaram as seguintes temáticas principais, respectivamente: $1^{\circ}$ - Saúde com $40,8 \%$ de média se contabilizados os percentuais de todas as pesquisas; $2^{\circ}$ - Segurança (23,4\%); $3^{\circ}$ - Educação (8,2\%); $4^{\circ}$ Trânsito - Mobilidade Urbana (6,2\%); e $5^{\circ}$ - Calçamento de ruas e avenidas Infraestrutura Urbana (5,2\%).

Duas constatações iniciais podem ser observadas a partir da análise dos dados. A primeira é o fato de se ter estabilidade com relação aos temas que ocuparam as cinco primeiras colocações nas respostas dos curitibanos. Em todas as pesquisas divulgadas, os cinco temas que ocuparam as cinco primeiras colocações não se alteraram. Não surgiram outros temas na lista dos principais problemas enfrentados pelo eleitor.

O que ocorreu foi uma pequena variação de posição dentro do ranking. Saúde, Segurança e Educação ficaram, respectivamente, em $1^{\circ}, 2^{\circ}$ e $3^{\circ}$ lugares em todos os relatórios divulgados. As únicas alterações foram com as temáticas Trânsito e Infraestrutura. Trânsito ocupando a $5^{\circ}$ colocação na primeira pesquisa, mas passando para a quarta colocação a partir da segunda, divulgada em 10/08. O contrário ocorreu com a temática Infraestrutura. Entretanto, na quarta e quinta pesquisas, as duas temáticas ficaram empatadas no percentual de respostas dos entrevistados. O que se podemos destacar, a partir do exposto, é a estabilidade durante todo o período pré-eleitoral e eleitoral das respostas dos eleitores em relação aos principais problemas. 
O cálculo da média dos percentuais atribuídos a cada temática coloca Saúde como a principal problema, com ampla vantagem sobre os demais. $\mathrm{O}$ assunto chegou a aparecer com mais que o dobro de percentual do segundo colocado ( $46 \%$ a $20 \%$, na pesquisa divulgada dia 24/08, três dias após o início da veiculação do HGPE).

Com relação ao segundo tema mais registrado, Segurança, confirmamos também a permanência da indicação do eleitor, dada a diferença entre o segundo e o terceiro colocados. Diferença que chegou a 25\% em 10/08 e que, na média, foi superior a 15\%. Se levada em consideração a margem de erro das pesquisas, Saúde e Segurança empataram tecnicamente na aferição de agosto.

Dada a constância das respostas, podemos inferir as duas temáticas como as que dominavam as preocupações dos eleitores durante o período aferido. O índice das temáticas que ocuparam entre a terceira e a quinta colocação variou de $5 \%$ a $10 \%$, ficando distante das primeiras colocadas, o que demonstra preocupação menor do eleitor com Saúde e Segurança, se compararmos com Educação, Trânsito e Infraestrutura.

\section{COMPARATIVO ENTRE HGPE DE RÁDIO E TV}

A categorização quantitativa dos assuntos abordados pelos candidatos durante a veiculação do HGPE tanto em rádio quanto em TV, pelos candidatos Luciano Ducci, Gustavo Fruet e Ratinho Junior durante o primeiro turno das eleições para prefeito de Curitiba em 2012, apresentou os seguintes resultados:

Tabela 2 - Comparação das temáticas no HGPE dos prefeitos de Curitiba em 2012 (em \%)

\begin{tabular}{c|c|c|c|c|c|c}
\hline \hline Temáticas & \multicolumn{4}{|c|}{ Rádio } & \multicolumn{3}{c}{ Televisão } \\
\hline Adm. Pública & 1,8 & 1,8 & 5,3 & 6,7 & 0,6 & 7,7 \\
\hline Assistência Social & 8,2 & 2,4 & 0,8 & 9,2 & 4,5 & 5,4 \\
\hline Cidade & 2,8 & - & 6,4 & 7,1 & 9,2 & 4,6 \\
\hline Desqualificação & 7,3 & 4,3 & 4 & 1,8 & 5 & 3,5 \\
\hline Educação & 7,7 & 10,7 & 6,6 & 7,1 & 7,8 & 7,3 \\
\hline Infraestrutura & 2,7 & 1,1 & 0,9 & 9,3 & - & 2,4 \\
\hline
\end{tabular}


TESSEROLI, Ricardo \& PANKE, Luciana. Quando a voz do eleitor pouco ecoa para os candidatos: estudo de caso do HGPE em Curitiba 2012.

\begin{tabular}{c|c|c|c|c|c|c}
\hline Mobilidade Urbana & 6,3 & 7,9 & 6,3 & 9,2 & 7,1 & 2,4 \\
\hline Saúde & 6,8 & 14,2 & 6,8 & 11,2 & 12,3 & 2,8 \\
\hline Segurança & 3,1 & 5,1 & 3,1 & 3,9 & 2,8 & 1,4 \\
\hline \hline
\end{tabular}

Fonte: PANKE, LINS NETO e TESSEROLI (2013).

Inicialmente, por meio da análise dos dados da tabela podemos extrair quais foram as temáticas mais abordadas pelos três candidatos no HGPE de rádio e de TV.

No rádio, Luciano Ducci priorizou a temática Assistência Social, com 8,2\% do tempo, seguido de Educação com 7,7\%. O tema Desqualificação apareceu em terceiro com 7,3\% seguido de Saúde e Mobilidade Urbana, com 6,8\% e 6,3\% respectivamente. É possível constatar uma visível diferença entre as temáticas abordadas pelo candidato na televisão. Neste meio de comunicação, Ducci priorizou a Saúde, com 11,2\% do tempo do HGPE. Em segundo ficou Infraestrutura (9,3\%). O terceiro, quarto e quinto lugar foram ocupados respectivamente por Assistência Social (9,2\%), Cidade (7,1\%) e Educação (7,1\%). Vale destacar que, embora tenha o maior tempo de HGPE, com quase 11 minutos de propaganda eleitoral, Luciano Ducci não conseguiu votos suficientes para disputar o segundo turno das eleições.

Gustavo Fruet priorizou a temática Saúde no rádio, com 14,2\% do tempo dos programas, seguido de Educação (10,7\%), Mobilidade Urbana (7,9\%), Segurança (5,1\%). Desqualificação apareceu em quinto com 4,3\% do tempo total do HGPE de rádio. Na TV, a campanha de Fruet se mostrou mais semelhanças com a campanha de rádio, do que se comparado aos dados da campanha de Ducci. As cinco temáticas mais abordadas foram, respectivamente: Saúde (12,3\%), Cidade (9,2\%), Educação (7,8\%) Mobilidade Urbana (7,1\%) e desqualificação (5\%).

No rádio, a campanha de Ratinho Junior, teve como temática mais abordada Saúde, com 6,8\%, seguida de Educação (6,6\%), Cidade (6,4\%), Mobilidade Urbana (6,3\%) e Administração Pública (5,3\%). Em primeiro lugar no HGPE de TV de Ratinho Junior ficou Administração Pública (7,7\%), seguido de educação em segundo (7,3\%), Assistência Social em terceiro $(5,4 \%)$, Cidade $(4,6 \%)$ e Desqualificação $(3,5 \%)$ em quarto e quinto lugares respectivamente.

$\mathrm{Na}$ comparação entre os candidatos constatamos diferentes estratégicas e pulverização de temáticas. Saúde, Educação e Mobilidade Urbana, apareceram entre as cinco 
principais temáticas abordadas pelos três candidatos no rádio. $\mathrm{Na}$ TV as temáticas que coincidiram foram Educação e Cidade.

Ducci, no rádio, priorizou assuntos que tem ligação com as classes sociais mais baixas como Assistência Social, Educação, Saúde e Mobilidade. Na TV, além dos assuntos citados, também deu ênfase nas ações de infraestrutura. Uma ressalva à temática desqualificação deve ser feita, foi a campanha de Ducci que teve o maior percentual dessa temática $(7,3 \%)$ no rádio.

A campanha de Fruet no rádio também priorizou temas mais próximos das classes sociais mais baixas e enfatizou Saúde nos dois meios. Desqualificação ocupou o quinto lugar entre os mais citados tanto da TV quanto do rádio. Freut foi o único que tratou de Segurança entre as cinco mais citadas, neste caso, na quinta colocação do HGPE de rádio.

Por sua vez, Ratinho Junior foi o único que incluiu a Administração Pública entre as cinco mais valorizadas entre o rádio e TV. A temática Saúde, mais tratada no rádio, nem chegou a ficar entre as cinco principais no HGPE de TV. Assistência Social, a terceira mais citada no HGPE de TV, com 5,4\%, teve somente $0.8 \%$ do tempo total do HGPE de rádio, não entrando para o ranking dos assuntos em destaque.

Tanto Ratinho Junior quanto Ducci tiveram sete temáticas entre as cinco mais citadas entre o rádio e TV. Na campanha de Ducci essa concentração foi ainda maior, com apenas seis temas ocupando os cinco mais citados entre o rádio e TV.

\section{PESQUISAS E HGPE}

Nas pesquisas, como destacamos anteriormente, as demandas eram por $1^{\circ}$ Saúde; $2^{\circ}$ Segurança; $3^{\circ}$ Educação; $4^{\circ}$ Trânsito-Mobilidade Urbana; e $5^{\circ}$ Calçamento de ruas e avenidas Infraestrutura Urbana. A partir do exposto, percebemos equivalência entre os assuntos reivindicados como os maiores problemas dos curitibanos e as principais temáticas do HGPE de rádio e TV. De todas as temáticas apontadas, somente Educação, terceira no ranking de acordo com as pesquisas, esteve entre as principais abordagens dos candidatos analisados.

A temática Saúde só não esteve entre as cinco principais temáticas abordadas na campanha de TV de Ratinho Junior, mesmo assim, no geral, ficou com um percentual muito abaixo do apontado pelas pesquisas do Ibope. Na média, Saúde era assinalado por 40,8\% 
dos entrevistados como principal dificuldade de Curitiba, enquanto a maior abordagem do tema não passou de 14,2\%, isso no HGPE de rádio de Gustavo Fruet.

Ainda que indicada como segundo principal problema de Curitiba, para 23,4\% dos eleitores curitibanos, Segurança só apareceu entre as principais temáticas no HGPE de rádio do candidato Gustavo Fruet. O mesmo pode ser dito do tema Infraestrutura, registrado como o quinto maior problema que a capital paranaense enfrentava, só esteve nos programas de Luciano Ducci e somente na TV. Percebemos, também, a ausência da temática Mobilidade Urbana no HGPE de Luciano Ducci e Ratinho Junior.

\section{CONSIDERAÇÕES FINAIS}

A construção de planos de governo e das estratégias eleitorais não dependem unicamente de pesquisas de opinião pública. Outros fatores como o contexto socioeconômico, acordos entre partidos, financiadores de campanha, perfil do candidato e outros grupos de pressão interferem nas escolhas. A pesquisa apresentada neste trabalho, procurou estudar a relação entre os conteúdos das pesquisas de opinião pública e os veiculados no Horário Gratuito de Propaganda Eleitoral considerando a hipótese de que as demandas da população, aferidas pelos Institutos, estariam contempladas nos programas dos candidatos.

Para isso, o estudo contemplou a eleição do prefeito de Curitiba, em 2012, cujo pleito, pela primeira vez, esteve entre três potenciais candidatos: Gustavo Fruet (PDT) (que se elegeu), Luciano Ducci (PSB) e Ratinho Jr (PSC). A metodologia empregada foi Análise de Conteúdo para verificar as temáticas (Administração Pública; Assistência Social; Candidato; Cidade; Desqualificação; Educação; Esporte, Lazer e Cultura; Infraestrutura; Meio ambiente; Mobilidade Urbana; Saúde; Segurança e Religião) apresentadas nos programas dos candidatos e os dados expostos nas cinco pesquisas de intenção de voto realizadas pelo Ibope. Os relatórios que compuseram o corpus para análise quantitativa foram divulgados entre os dias 29 de março e 03 de outubro de 2012. Todos os programas dos três candidatos foram transcritos e as temáticas contabilizadas, conforme as tabelas apresentadas no texto.

A partir da análise e comparação de todos os dados, observamos que a opinião da população Curitiba poderia ter sido mais levada em consideração nas estratégias de comunicação do HGPE dos principais candidatos a prefeito. Constatamos correspondência 
entre o que os eleitores gostariam que fosse tratado no HGPE e o que nos candidatos apresentaram. Porém, é nítido que o percentual das temáticas, principalmente de Saúde, Educação e Segurança, ficou aquém do que o eleitor esperava que fosse apresentado pois os dados demonstraram que a abordagem das temáticas não foi proporcional a importância dada pelos eleitores.

Houve semelhança do que foi defendido pelas campanhas com o que a população esperava, entretanto, isto não significou que os assuntos estivessem tratados em grande dimensão. Podemos inferir que as pesquisas apoiaram o direcionamento dos temas dos programas, contudo, essas informações ficaram conciliadas com outras estratégias de posicionamento. Isso explicaria, por exemplo, a porcentagem alta de Desqualificação nos programas. Outra explicação para esta informação, é o próprio aspecto competitivo do pleito, quando os candidatos partem para a campanha negativa, buscando apontar defeitos dos seus oponentes, do seu grupo político ou de sua visão de cidade.

Nas pesquisas, os números indicaram que $1^{\circ}$ Saúde; $2^{\circ}$ Segurança; $3^{\circ}$ Educação; $4^{\circ}$ Trânsito-Mobilidade Urbana; e $5^{\circ}$ Calçamento de ruas e avenidas Infraestrutura Urbana estavam entre as principais preocupações dos curitibanos. Apenas Educação esteve contemplada como uma temática prioritária nos programas dos três candidatos. Outro dado importante a destacar é a diferenciação de mídia em relação aos temas. Observamos que as candidaturas podem haver levado em consideração as características de rádio e de TV na difusão dos conteúdos, contemplando os respectivos públicos e horários de veiculação.

A pesquisa, portanto, focou-se em um dos aspectos condutores das estratégias de comunicação eleitoral concluindo que a relação entre pesquisa de opinião pública e conteúdos programáticos estão vinculados, mas ainda com influências de outros fatores na construção das narrativas. A hipótese do estudo se confirmou parcialmente, relativizando que uma campanha deve ouvir o cidadão, entretanto, isso pode ocorrer de outras formas e também há de se considerar outros materiais de campanha e fatores que explicariam o não seguimento integral das demandas apontadas nas pesquisas.

\section{REFERÊNCIAS}

ALBUQUERQUE, A. 1999. Aqui você vê a verdade na tevê: propaganda politica na televisão. Niterói, MCII. 
ALBUQUERQUE, A. 2004. Propaganda política e eleitoral. In. ALBINO, A.; RUBIM, C. Comunicaşão Politica: conceitos e abordagens. Salvador, Edufba.

ALMEIDA, C, A 2008. A cabeça do eleitor. Rio de Janeiro; Editora FGV.

BAQUERO, M. 1995. Opinião pública e pesquisas eleitorais. In: BAQUERO, M. (Org.). Brasil - transição, eleições e opinião pública. Porto Alegre: Editora da UFRGS.

CERVI, E. 2010. U. HGPE: de demarcador do "tempo da política" a indicador de distribuição de recursos partidários nas eleições brasileiras. Em Debate. Belo Horizonte. v. 1, p. 8-23.

CERVI, E. U.; MASSUCHIN, M. G. 2013. Metodologia quantitativa em pesquisas sobre cobertura jornalística. Revista Famecos: Porto Alegre, v. 20, n. 3, pp. 840-865.

DOWNS, A. 2002. Uma teoria econômica da democracia. São Paulo: EDUSP.

JORGE, V, L. 1997. Os meios de comunicação de massa nas campanhas eleitorais. Comunicação \& Política, Rio de Janeiro, v. IV, p. 126-133.

LAVAREADA, A. 2009. Emoções ocultas: estratégias eleitorais. São Paulo: Objetiva.

MAGALHÃES, R.F. 1995. A ciência política e o marketing eleitoral: algumas elaborações teóricas. Revista Comunicação \& Política, Rio de Janeiro, vol. I, n 3, p. 127 139.

MIGUEL. L. F. 2004. Discursos cruzados: telenoticiários, HGPE e a construção da agenda eleitoral. Revista Sociologias, Porto Alegre, ano 6, n. 11, p. 238-258.

OLIVEIRA, A. ROMÃO, M. C. GADELHA, C. 2012. Eleições e Pesquisas eleitorais: desvendando a caixa preta. Curitiba. Juruá.

PAIVA, D. 2010. A reconfiguração da campanha eleitoral na era da tecnicidade: a propaganda televisiva no Brasil e no México em 2006. 210 f. Tese (Doutorado em Ciência Política) Universidade Federal de Minas Gerais.

PANKE, L; CERVI, E. 2011 Análise da comunicação eleitoral -uma proposta metodológica para os estudos do HGPE. Contemporânea. Salvador, v.09, n03, p. 390-404.

PANKE, L. et al. 2013. Levantamento Temático da Propaganda Eleitoral na Televisão: estudo de caso sobre as eleições municipais de Curitiba em 2012. In Anais Congresso da Associação Brasileira de Pesquisadores em Comunicação e Política. 4, Curitiba. p. 01-22. Disponível em: http://www.compolitica.org/home/wp-content/uploads/2013/05/GT-09-Propaganda-eMarketing-Pol\%C3\%ADtico-Luciana-Panke.pdf. Acesso em: 28/10/2014.

PERHS, L; LEAL P.R. 2013 Horário gratuito de propaganda eleitoral e propaganda partidária gratuita: do surgimento à personalização na televisão brasileira. In Revista Parágrafo. São Paulo, v. 2, n. 1 p.84-97. 
ROMÃO, M. C. 2010. A Dinâmica Eleitoral no Brasil: Fórmulas, Competição e Pesquisas. Recife: Edição do Autor.

SCHMITT, R et al. 1999. Estratégias de campanha no horário gratuito de propaganda eleitoral em eleições proporcionais. Revista Dados, Vol. 42, nº2, p. 277-302.

SILVEIRA, F. E. 2000. A dimensão simbólica da escolha eleitoral. In: FIGUEIREDO, O. Marketing político e persuasão eleitoral. São Paulo: Konrad Adenauer.

VEIGA, L. Em Busca de Razões para o Voto: o uso que o homem comum Faz do horário eleitoral. Tese (Doutorado em Ciência Política). Instituto Universitário de Pesquisas do Rio de Janeiro IUPERJ. 